\title{
O DIREITO À LIBERDADE FEMININA NA PRÁTICA DO ABORTO ATÉ O 3 MÊS DE GESTAÇÃO À LUZ DA DECISÃO DO SUPREMO TRIBUNAL FEDERAL BRASILEIRO PARA ADOÇÃO DE POLÍTICAS PÚBLICAS
}

\author{
THE RIGHT TO FEMALE LIBERTY IN THE PRACTICE OF ABORTION \\ UNTIL THE 3rd MONTH OF GESTURE IN THE LIGHT OF THE \\ DECISION OF THE BRAZILIAN SUPREME COURT FOR THE ADOPTION \\ OF PUBLIC POLICIES
}

\author{
Cleber Sanfelici Otero ${ }^{\mathrm{I}}(\mathbb{0})$ \\ Alessandra Trevisan Ferreira ${ }^{\mathrm{II}}$ (1)
}

I Universidade Cesumar, Maringá, PR, Brasil. Doutor em Sistema Constitucional de Garantia de Direitos. E-mail: cleberot@ yahoo.com.br

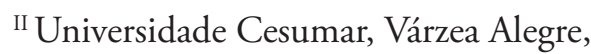
CE, Brasil e Faculdade Pitágoras, Londrina, PR, Brasil. Mestranda em Ciências Jurídicas. E-mail: aletrevi18@ hotmail.com

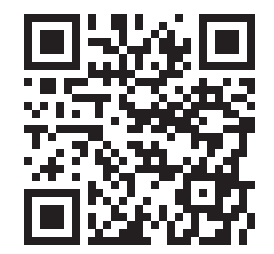

DOI: http://dx.doi.org/10.31512/rdj.v20i38.160

Recebido em: 11.12.2018

Aceito em: 12.08.2019
Resumo: A colisão entre o direito fundamental à vida e a liberdade feminina na prática do abortamento é objeto deste artigo. Embora o ordenamento jurídico brasileiro considere provocar aborto um crime contra a vida, não há como desconsiderar o grave sofrimento a que se submetem as mulheres que carregam no ventre um feto indesejado, em flagrante violação à dignidade humana, principalmente quando não há condições econômicas de manutenção da criança que está por vir. É realizada uma análise dos fundamentos adotados na decisão do Supremo Tribunal Federal, que autorizou a interrupção da gravidez até o $3^{\circ}$ mês da gestação, em especial quanto à ausência de políticas públicas de esclarecimento e proteção às mulheres no Brasil. Ao final, é analisado o processo de formulação e as consequências gerais dos programas institucionalizados pelo governo federal no âmbito da saúde da mulher, a saber, a Rede Cegonha e o Sistema Nacional de Cadastramento e Acompanhamento de Gestantes e Puérperas.

Palavras-chave: Direito à vida. Dignidade humana. Aborto. Políticas Públicas.

Abstract: The collision between the fundamental right to life
and the female liberty in the practice of abortion is presented
in this article. Although the Brazilian legal system considers
abortion a crime against life, there is no way to disregard the
serious suffering to which women who carry in the womb
an unwanted fetus in flagrant violation of human dignity,
principally when there are no economic conditions for
maintenance of the coming child. An analysis of the grounds
adopted in the decision of the Federal Supreme Court that
authorized the interruption of pregnancy up to the third
month of gestation was carried out, especially regarding the 


\begin{abstract}
absence of public policies to clarify and protect women in Brazil. At the end, the formulation process and the general consequences of the programs institutionalized by the federal government in the field of women's health are analyzed, namely the Stork Network and the National Registration and Monitoring System for Pregnant women and Postpartum Women.
\end{abstract}

Keywords: Right to life. Human dignity. Abortion; Public Policies.

\section{Consideraçóes iniciais}

Torna-se necessária uma análise da questão do direito à liberdade feminina para a prática de abortamento, em especial após a decisão do Supremo Tribunal Federal (STF), que autorizou a interrupçáo da gravidez até o $3^{\circ}$ mês de gestação, sob o fundamento jurídico de que o problema não é criminal, mas sim a ausência de políticas públicas direcionadas exclusivamente às mulheres.

Para tanto, é relevante realizar a abordagem acerca do direito à vida e à dignidade da pessoa humana, direitos em contraposição na questão, porquanto há direito tanto da gestante como também do feto, este último vitimado em face de sua vida poder ser ceifada.

A proposta do trabalho consiste em versar sobre o tema em comento, com um estudo no que diz respeito aos bens jurídicos tutelados e relacionados com o crime de aborto, a saber, direito à vida, à liberdade e à dignidade humana, os quais normalmente entram em colisão na matéria. Em contraposição à liberdade da mulher quanto à escolha em manter ou não a gestaçáo, apresenta-se a postura religiosa frente à discussão, com a análise principalmente dos argumentos das igrejas católica e evangélicas, porquanto prevalentes na República Federativa do Brasil.

Na sequência, será estudado o conceito e realizada uma reflexão sobre a dignidade da pessoa humana, estabelecida como princípio fundamental na Constituição Federal brasileira de 1988. O conceito de abortamento, do crime de aborto praticado, bem como do bem jurídico tutelado, as formas de abortamento, os tipos de aborto legal e a sua classificação serão apresentados em seguida. Nos tópicos finais, será contextualizada a decisão do STF que autorizou a interrupçáo da gravidez até o terceiro mês da gestação, bem como será analisada a necessidade de adoção de políticas públicas na saúde e especialmente voltadas às mulheres.

Dessa forma, além de se fazer uma análise do direito à vida e evidenciar o direito da mulher ao seu próprio corpo, a problemática norteadora que envolve esta pesquisa revela-se em razão da pergunta que ora se faz: o abortamento é questão de política pública ou do âmbito criminal? Para respondê-la, há utilização do método exploratório com pesquisa teórica, bibliográfica, doutrinária e jurisprencial acerca da matéria. O método 
de abordagem dedutivo é empregado para uma análise do problema referente à prática do aborto a partir do princípio da dignidade humana e da liberdade da mulher em colisão com o direito fundamental à vida do feto para, em seguida, proceder à caracterização ou não da prática de crime.

\section{Histórico no mundo}

O abortamento nem sempre foi objeto de inculpação, pois entre os hebreus e os gregos a sua realização era muito frequente. Em Roma, a Lei das XII Tábuas e as leis da República não incriminavam ou regiam o aborto, pois julgavam a concepção como uma das partes do corpo da gestante e reconheciam que as mesmas tinham certa autonomia, pois a mulher que provocava o aborto nada mais fazia do que exercer um direito, isto é, dispor do próprio corpo. Posteriormente, todavia, o abortamento passou a ser considerado como uma violaçáo ao direito do esposo à sua descendência, com a punição de sua prática (CAPEZ, 2014, p. 145). Com isso, a mulher solteira (nubile iuris sui) foi liberada a abortar, mas a mulher casada que abortava praticava uma ofensa ao seu esposo.

Com o advento do cristianismo, a compreensão do abortamento mudou completamente, como bem esclarece Fernando Capez (2014, p. 145):

Foi então com o cristianismo que o aborto passou a ser efetivamente reprovado no meio social, tendo os imperadores Adriano Constantino e Teodósio reformado o direito e assimilado o aborto criminoso ao homicídio. Na Idade Média, o teólogo Santo Agostinho, com base na doutrina de Aristóteles, considerava que o aborto seria crime apenas quando o feto tivesse recebido alma, o que se julgava ocorrer quarenta ou oitenta dias após a concepção, segundo se tratasse de varão ou mulher. São Basílio, no entanto, não admitia qualquer distinção considerando o aborto sempre criminoso. É certo que, em se tratando de aborto, a Igreja sempre influenciou com os seus ensinamentos na criminalização do mesmo, no entanto, não admitia qualquer distinção considerando o aborto sempre criminoso.

Com fundamento em concepção cristã, no início do século IV, os atos dos imperadores romanos Adriano e Teodósio vieram a compreender o aborto como morte do ser humano, com a equiparação do aborto ao delito de homicídio e entendimento de que os dois crimes teriam que ter as mesmas penas (PRADO, 2011, p. 128), mas foi o Édito de Valenciano o primeiro documento a condenar o aborto, quando praticado com o consentimento da gestante, como crime punido com pena capital. Da mesma forma, o Código Justiniano punia quem, por interesses econômicos, praticasse o aborto. O Imperador Setimus Severus equiparou o aborto ao homicídio, imputando pena de morte a quem o fizesse (SÁ, 2002, p. 444).

$\mathrm{Na}$ Idade Média, os teólogos divergiam acerca da prática do aborto. Consoante Santo Agostinho, com base na doutrina aristotélica, só haveria o delito em se tratando de 
feto animado, o que ocorria 48 horas dias após a concepção. Em opinião contrária, São Basílio (374 d.C.) afirma que o aborto praticado sempre seria crime (PRADO, 2011, p. 128).

Pouco a Igreja Católica mudou desde então, pois continua a desaprovar o ato de provocar aborto, segundo Dworkin (2009, p. 54), náo sob o fundamento de ser o feto uma pessoa com direito à vida, mas em razão do abortamento ser considerado um insulto ao dom divino de criar a vida.

A Igreja influenciou sobremaneira o direito de vários países, inclusive do Brasil, náo apenas pelo ato de provocar aborto ter sido transformado em crime, mas até mesmo pela forma como a religião bloqueia as tentativas de adoção do caminho inverso.

\section{Histórico no Brasil}

Inicialmente, o abortamento praticado pela gestante náo era tipificado como crime no Brasil, pois o Estado considerava que a mulher era proprietária do seu corpo e poderia livremente dele dispor, inclusive com a faculdade de interromper ou não a sua gravidez, sem nenhum tipo de sanção.

O ato de provocar aborto foi categorizado como crime grave, no nosso ordenamento jurídico, a partir do Código Criminal do Império de 1830, incluso entre os crimes contra a segurança da pessoa e de um bem primordial, qual seja, a vida. Os arts. 199 e 200 do Código do Império do Brasil (BRASIL, 1878, p. 48) detalhavam dois tipos de figuras criminosas, a saber, o aborto sofrido e o aborto consentido, sob esta mesma ótica, e o que se compreendia na época, pois o aborto provocado pela própria gestante não era punido:

Art. 199. Ocasionar aborto por qualquer meio empregado anterior ou exteriormente com o consentimento da mulher pejada. Pena: Prisão com trabalho de 1 a 5 anos. Se o crime for cometido sem o consentimento da mulher pejada. Penas dobradas.

Art. 200. Fornecer, com o consentimento de causa, drogas ou quaisquer meios para produzir o aborto, ainda que este não se verifique. Pena: Prisão com trabalho de 2 a 6 anos. Se esse crime for cometido por médico, boticário ou cirurgiấo ou ainda praticantes de tais artes. Penas: dobradas.

O Código Penal de 1830 punia apenas quem praticava o ato de abortar, mas não quem o consentia, com a pena variava de 1 a 5 anos, sendo dobrada se acaso fosse praticado sem o consentimento da mulher. Não se punia o autoabortamento, sendo a gestante daquela época imune a qualquer tipo de punição.

No ano de 1890, passou a viger o Código Penal da República, que "criminalizou" o abortamento provocado pela própria gestante, diferenciando-o do abortamento com expulsão do feto, bem como do agravamento se, por acaso, houvesse a morte da mulher gestante. 
Cezer Roberto Bitencourt (2007, p. 129) aduz:

Quando o aborto era praticado para ocultar desonra própria a pena era consideravelmente atenuada. Este código passou a autorizar o aborto para salvar a vida da gestante, neste caso, punia eventualmente imperícia do médico ou parteira que culposamente causassem a morte da gestante.

Com o advento do Código Penal de 1890 (BRASIL, 1890), passou-se a punir a imperícia do médico ou daquele que praticasse o abortamento, servindo inclusive como atenuação da pena se o aborto resultasse para ocultar desonra própria. Restou também autorizado o abortamento para salvar a vida da gestante. Outrossim, a legislação já fazia distinção entre o abortamento com e sem expulsão do feto, cominando a pena mais grave quando havia a expulsão. E as penas eram aumentadas em caso de morte da mulher:

Art. 300.

Provocar abôrto haja ou não a expulsão do fructo da concepção:

No primeiro caso: - pena de prisão cellular por dous a seis annos.

No segundo caso: - pena de prisão cellular por seis mezes a um anno.

$\$ 1^{\text {o }} \mathrm{Si} \mathrm{em}$ consequencia do abôrto, ou dos meios empregados para provocal-o, seguir-se a morte da mulher:

Pena - de prisão cellular de seis a vinte e quatro annos.

$\$ 2^{\circ} \mathrm{Si}$ o abôrto for provocado por medico, ou parteira legalmente habilitada para o exercicio da medicina:

Pena - a mesma precedentemente estabelecida, e a de privação do exercicio da profissão por tempo igual ao da condemnação.

Art. 301. Provocar abôrto com annuencia e accordo da gestante:

Pena - de prissão cellular por um a cinco annos.

Paragrapho unico. Em igual pena incorrerá a gestante que conseguir abortar voluntariamente, empregado para esse fim os meios; e com reducção da terça parte, si o crime for commettido para occultar a deshonra propria.

O Código Penal atualmente vigente tipificou várias figuras ou maneiras de praticar aborto, consoante se observa nos arts. 124, 125, 126, 127 e 128, seja para punir o aborto provocado, o aborto sofrido e o aborto consentido, respectivamente.

Sobre o Código em comento, disserta Bitencourt (2007, p. 129):

O código penal de 1940 foi publicado segundo a cultura, costume e hábitos na década de 30. Passaram mais de 60 anos, e, nesse lapso, não foram apenas os valores da sociedade que se modificaram, mas principalmente os avanços científicos e tecnológicos, que produziram verdadeira revolução na ciência médica. No atual estágio, a medicina tem condiçôes de definir com absoluta certeza e precisão, eventual anomalia, do feto e, 
consequentemente, a viabilidade da vida extra-uterina. Nessas condiçóes, e perfeitamente defensável a orientação do anteprojeto de reforma da parte especial do Código Penal, que autoriza o aborto quando o nascituro apresentar graves e irreversíveis anomalias físicas ou mentais, ampliando a abrangência do aborto eugênico ou piedoso.

Destarte, no decorrer de todos esses anos, desde o Código Imperial de 1830 até o atual vigente, sendo este o de 1940, muitas mudanças ocorreram no que tange ao "aborto", tendo como a principal causa os avanços científicos. As mudanças foram de grande valia para o ordenamento pátrio, fundamental para norteador e assegurar a preservação da humanidade.

\section{A questáo do abortamento ante a postura religiosa}

A Igreja Católica é totalmente contra a prática do ato de abortar, sob o fundamento de que é a própria vida que gera o dever de proteção. Apesar de ser contra provocar o aborto, no entanto, o clero tem a consciência de que o assunto está ligado à sociedade, sem negligenciar para o fato de que cada sociedade tem a sua lei. Em alguns países, o abortamento é totalmente vedado, em outros, parcialmente, e em outros ele é totalmente permitido.

Mesmo nos países em que o abortamento provocado é permitido ou parcialmente permitido, a Igreja Católica é totalmente contra a prática, utilizam-se do ditado de que "nem sempre aquilo que é legalmente aceito é moralmente lícito". O Catecismo da Igreja Católica ensina:

Os direitos inalienáveis da pessoa devem ser reconhecidos e respeitados pela sociedade civil e pela autoridade política. Os direitos do homem não dependem nem dos indivíduos, nem dos pais, e também não representam uma concessão da sociedade e do Estado pertencem à natureza humana e são inerentes à pessoa em razão do ato criador do qual esta se origina. "Entre estes direitos fundamentais é preciso citar o direito à vida e à integridade física de todo ser humano, desde a concepção até a morte” (CIC \$2272).

Desde o século I, a Igreja sempre afirmou a maldade moral de todo aborto provocado. Esta forma de compreender a questão não foi alterada. O aborto direto, quer dizer, querido e provocado como um fim ou como um meio, é gravemente contrário à lei moral:

Não matarás o embrião por aborto e não farás perecer o recém-nascido. Deus, senhor da vida, confiou aos homens o nobre encargo d preservar a vida, para ser exercido de maneira condigna ao homem. Por isso a vida deve ser protegida com o máximo cuidado desde a concepção. O aborto e o infanticídio são crimes nefandos. (CIC \$2271)

A Igreja Católica não apresenta maleabilidade com a prática do aborto e, desde o século I até os dias atuais, o seu entendimento continua o mesmo, invariável, condenando quem o pratica, praticamente um dogma. É evidente que a Igreja não virará as costas para quem pratica o delito, pois não rejeita nenhum pecador, como um hospital para abrigar 
e ajudar aquelas pessoas que necessitam, por serem "doentes da alma". Afinal, aqueles que praticam o aborto ou qualquer outro pecado devem ser trazidos de volta ao rebanho. A maior parte das Igrejas Evangélicas adota postura semelhante, de forma contrária ao aborto.

A República Federativa do Brasil é, no entanto, um Estado laico.

\section{0 direito à vida}

O direito à vida é um direito fundamental assegurado pela Constituição Federal de 1988, ao determinar, no art. $5^{\circ}$, caput, in verbis: "todos são iguais perante a lei, sem distinção de qualquer natureza, garantindo-se aos brasileiros e aos estrangeiros residentes no país a inviolabilidade do direito à vida, [...]” (BRASIL, 1988).

Acerca da essencialidade deste direito, Diniz (2007, p. 20) descreve:

O direito à vida, por ser essencial ao ser humano, condiciona os demais direitos da personalidade. A Constituição Federal de 1988 , em seu art. $5^{\circ}$, caput, assegura a inviolabilidade do direito à vida, ou seja, a integralidade existencial, consequentemente, a vida é um bem jurídico tutelado como direito fundamental básico desde a concepção, momento específico, comprovado cientificamente, da formação da pessoa.

Embora não seja absoluto, todo o ser humano tem direito à vida, de modo que ninguém pode dela ser privado, exceto em casos excepcionais, como é a hipótese da pena de morte em caso de guerra externa declarada ou se houver a colisão com princípios e outros direitos fundamentais.

Além de o direito à vida estar previsto em norma constitucional, trata-se de direito fundamental sedimentado por cláusula pétrea, conforme o art. $60, \$ 4^{\circ}$, inciso IV, da Constituição de 1988, de maneira que não pode ser abolido nem por Emenda Constitucional.

Não só a Constituiçáo Federal de 1988 prevê acerca da inviolabilidade do direito à vida, como também acordos internacionais sobre Direitos Humanos dos quais o Brasil é signatário, acordos estes que afirmam que o direito à vida é inviolável.

A Convenção Americana de Direitos Humanos, que desde o Decreto no 678/1992 faz parte do ordenamento jurídico brasileiro, ora com o status de norma supralegal, também assegura a vida da pessoa, ao declarar, em seu art. $4^{\circ}, \mathrm{n}^{\circ} 1$, que "Toda pessoa tem o direito de que se respeite sua vida. Esse direito deve ser protegido pela lei e, em geral, desde o momento da concepçáo. Ninguém pode ser privado da vida arbitrariamente" (BRASIL, 1992).

Tem-se considerado indisponível o direito à vida, em especial por ser pré-requisito para a existência dos demais direitos aferidos constitucionalmente.

A proteção à vida tem dois planos: a dimensão vertical e a dimensão horizontal. 
A dimensão vertical engloba a proteção da vida nas distintas fases do desenvolvimento humano ( $\mathrm{da}$ fecundação à morte). Algumas acepçóes sobre o direito à vida arrazoam esta dimensão, pois este direito consistiria no "direito a não interrupção dos processos vitais do titular mediante intervenção de terceiros e, principalmente, das autoridades estatais" (DIMITRI, 2007, p. 397-399).

A dimensão horizontal, por sua vez, conglomera a qualidade da vida gozada, onde a mesma resulta no amparo do direito à saúde, educação, prestaçóes de seguridade social e, até mesmo, meio ambiente equilibrado, para garantir o direito à vida digna. Já para o Estado, a "inviolabilidade do direito à vida" resulta em três obrigaçóes, sendo elas a obrigação de respeito, a obrigação de garantia e a obrigação de tutela, conforme conceito apresentado por André de Carvalho Ramos (2014, p. 458):

A obrigação de respeito consiste no dever dos agentes estatais em não violar, arbitrariamente, a vida de outrem. A obrigação de garantia consiste no dever de prevenção da violação da vida por parte de terceiros e eventual punição àqueles que arbitrariamente violam a vida de outrem. A obrigação de tutela implica o dever do Estado de assegurar uma vida digna, garantindo condiçôes materiais mínimas de sobrevivência.

Por força da característica da complementaridade e da indivisibilidade dos direitos fundamentais, o direito à vida deve ser observado e analisado em conjunto com outros direitos fundamentais, por exemplo com o direito à integridade física e psíquica ou com o direito à saúde, mas sem ser negligenciado o conteúdo elementar de cada direito, numa simbiose a possibilitar a mais ampla proteçáo para as pessoas, consoante a importância e a indisponibilidade do bem jurídico prevista na Constituição Federal e na Convenção Americana de Direitos Humanos.

\section{Teorias acerca da origem da vida humana}

Existem posiçóes divergentes acerca do início da vida e de sua tutela.

Uma primeira corrente defende que a vida inicia com a penetraçáo do óvulo pelo espermatozoide, quando é formado o zigoto e, consequentemente, originado o mapa genético ao se estruturar a primeira célula humana. Náo se duvida de que a vida tem como pré-requisito a união dos gametas masculino e feminino, mas há divergência acerca do momento em que será viável a ponto de exigir tutela jurídica.

Contrária à teoria concepcionista, há a compreensão no sentido de que a vida humana começa posteriormente à concepção, distinguindo-se quanto a este momento, ou seja, se ocorre por ocasião do embrião se implantar no útero (teoria da nidaçáo), ou quando o sistema nervoso central está formado.

No ordenamento jurídico brasileiro, ante as normas existentes, o reconhecimento da personalidade jurídica ocorre em conformidade com a Teoria 
Natalista, ou seja, somente a partir do nascimento e com a respiração da criança, muito embora os direitos patrimoniais recebam proteção desde a concepção. A vida recebe proteçáo efetiva a partir da nidação, com a tipificação do crime de aborto desde este momento. A divergência maior acerca da proteção da vida ocorre quanto à circunstância de o embriáo estar ou náo estar implantado no útero materno, algo que envolve a ideia de vida viável em face das terminaçóes uterinas necessárias para que o feto venha a se desenvolver no processo vital até o nascimento.

O Código Civil, em seu art. $2^{\circ}$, prevê claramente que "a personalidade civil começa do nascimento com vida, mas a lei coloca a salvo, desde a concepção, os direitos do nascituro" (BRASIL, 2002). Por esta norma, o nascituro recebe proteçáo por ter as características humanas de uma pessoa em formação, inclusive para efeitos patrimoniais futuros, com a aquisição da personalidade jurídica. $\mathrm{O}$ nascituro deve receber proteção à vida, bem jurídico fundamental que deve ser assegurado, e, por tal razão, dever-se entender que é titular de direitos de caráter existencial. É como se o nascimento com vida tivesse uma eficácia retroativa, para confirmar os direitos eventualmente adquiridos desde a concepção, e não uma mera expectativa, pois os seus direitos são assegurados, inclusive de ordem patrimonial se o nascimento com vida se confirmar (VENOSA, 2014, p. 143).

Sob o tema, ensina-nos Pontes de Miranda (2000, p. 40) que o feto, embora receba proteção, não se torna pessoa se não nasce com vida, não adquire direitos e não se torna sujeito de direitos:

[...] Com o nascimento da personalidade (= entrada do nascimento do ser humano no mundo jurídico), nasce o direito à vida, como irradiação de eficácia do fato jurídico stricto sensu do nascimento do ser humano com vida (art. $4^{\mathrm{o}}, 1^{\mathrm{a}}$ parte). Nas leis penais e policias, muitas são as regras jurídicas que protegem a vida. Antes do nascimento, resguarda-se.

Para muitos doutrinadores, a referida legislação teria adotado a Teoria Concepcionista, para a qual o ser adquire status de humano a partir do momento da concepção, tendo em vista ser pela fecundação do óvulo humano o começo da vida. Procura-se, assim, justificar a titularidade de direitos para o embriáo desde a concepção.

A controvérsia acerca do começo da personalidade jurídica e da titularidade de direitos é explicada por Sílvio de Salvo Venosa (2014, p. 140) ao comentar o disposto no art. 20 do Código Civil:

[...] O atual Código refere-se à personalidade jurídica da "pessoa" nessa disposição. Em razão dos novos horizontes da ciência genética, procura-se proteger também o embriáo, segundo projeto que pretende já alterar essa dicção da presente lei. A questão é polêmica, ainda porque o embriáo náo se apresenta de per si como uma forma de vida sempre viável. A ciência ainda deve dar passos no sentido de fornecer ao jurista a exata concepção da dimensão do embrião como titular de alguns direitos. 
A questão do início da personalidade tem relevância porque, com a personalidade, o homem se torna sujeito de direitos.

No atual estágio do Direito brasileiro, somente adquire personalidade jurídica a pessoa que nasce e respira. $\mathrm{O}$ nascituro (feto) tem resguardados os seus direitos, que são confirmados por ocasião do nascimento com vida. A dúvida persiste quanto ao embrião formado em reprodução assistida e (ainda) não introduzido no ventre, porquanto é tãosó concepturo, mas não nascituro, apenas obtendo esta condição se futuramente vier a ser implantado no útero, com dificuldade para definir se há resguardo de direitos.

Ora, se a lei se preocupa com os direitos do nascituro desde a concepção, também diz respeito ao direito à vida, inclusive ao direito de poder viver, de maneira que todo o ataque à vida do embriấo pode também significar uma violação do direito mencionado, de tal forma que a reprodução assistida com formação excessiva de embriôes deveria ser coibida, especialmente se a finalidade não for a implantação uterina imediata.

Amplia-se a dúvida em razão dos avanços da ciência e dos novos métodos de concepção. A primeira bebê de proveta nasceu na Inglaterra em 1978, de maneira que, por ocasião da elaboração da Convenção Americana dos Direitos Humanos em 1969, ainda não havia a concepção in vitro, colocando-se em dúvida a proteção dos embriôes obtidos por meio de reprodução assistida, já que a realidade na ocasião do tratado internacional era outra, igualmente a finalidade da norma. O novo Código Civil foi promulgado em 2002, época em que os métodos de reprodução assistida já existiam e os embrióes assim concebidos também mereceriam proteção.

No Direito brasileiro, não há a proteção para os embriōes criopreservados e, com relação aos nascituros, não se reconhece a titularidade de direitos patrimoniais enquanto náo houver o nascimento e a confirmação da viabilidade vital com a respiração da pessoa. De qualquer forma, o bem jurídico vida é considerado fundamental e recebe proteção não apenas constitucional, mas também no âmbito criminal com o estabelecimento do crime de aborto.

Ao contrário do que parte da doutrina apregoa (DINIZ, 2011, p. 47), data venia, o direito à vida não é absoluto, porquanto a relatividade é característica dos direitos fundamentais, ainda mais em situações bem específicas nas quais este direito entra em conflito com outros valores ou com o direito também relevante de outras pessoas, casos em que é possível haver preferência diversa, com a devida e necessária fundamentação. 


\section{Dignidade da pessoa humana}

O princípio da dignidade da pessoa humana está previsto no art. $1^{\circ}$, inciso III, da Constituição Federal de 1988 e é considerado de suma importância, pois informa e orienta a aplicação de todos os direitos fundamentais e da personalidade.

Ao considerar o ser humano como um todo, num "eu” ontológico que transcende a matéria e atinge sentimentos, desejos, pensamentos e bens imateriais merecedores de tutela, Elimar Szaniawski (2005, p. 57-58) leciona que a ordem jurídica deve ser compreendida na integralidade, numa hierarquia de valores, na qual seja prevalente a noção de que o homem é pessoa dotada de dignidade e, consequentemente, demanda proteção da personalidade:

A personalidade humana consiste no conjunto de características da pessoa, sua parte mais intrínseca. [...] a ordem jurídica tem por principal destinatário o ser humano, protegendo a sua dignidade e garantindo-lhe o livre desenvolvimento da personalidade. Daí consistir o direito da personalidade em um direito subjetivo de categoria especial e de respeito a todo ser humano.

Um direito de tal grandiosidade e importância, que representa a parte intrínseca do ser humano, as manifestaçóes de sua personalidade, somente poderá encontrar tutela efetiva ao tornar-se uma cláusula geral pétrea. Por esta razão, a tutela da personalidade humana, por atentados praticados contra a mesma, não pode encontrar tutela plena somente no âmbito civil, devendo ser procurada, primeiramente, na Constituiçáo. [...]. O ser humano é o primeiro e principal destinatário da ordem jurídica e, através da teoria da repersonalização do direito civil, o direito se revela um sistema ético, tendo como centro o ser humano, como primeiro de seus valores, repousando os fundamentos do ordenamento jurídico dentro da noção de dignidade do ser humano.

Luiz Edson Fachin (2001, p. 190) esclarece ser a ideia de dignidade a estruturante do ordenamento jurídico:

[...] A dignidade da pessoa é princípio fundamental da República Federativa do Brasil. É o que chama de princípio estruturante, constitutivo e indicativo das idéias diretivas básicas de toda a ordem constitucional. Tal princípio ganha concretização por meio de outros princípios e regras constitucionais formando um sistema interno harmônico, e afasta, de pronto, a ideia de predomínio do individualismo atomista no Direito. Aplica-se como leme a todo o ordenamento jurídico nacional compondo-lhe o sentido e fulminando de inconstitucionalidade todo preceito que com ele conflitar.

O termo dignidade representa uma condição ínsita ao indivíduo, ou seja, algo que faz parte de sua natureza, algo que deve estar presente em seu dia-a-dia por intermédio de oferecimento de condiçóes fundamentais para uma vida saudável e no pleno exercício de seus direitos, conforme bem conceituada por Sarlet (2002, p. 233):

A qualidade intrínseca e distintiva reconhecida em cada ser humano que o faz merecedor do mesmo respeito e consideraçáo por parte do Estado e da comunidade, implicando, neste sentido um complexo de direitos e deveres fundamentais que assegurem a pessoa tanto contra todo e qualquer ato de cunho degradante e desumano como venham a lhe 
garantir as condiçôes existenciais mínimas para uma vida saudável, além de propiciar e promover sua participação ativa e responsável nos destinos da própria existência e da vida em comunhão com os demais seres humanos.

A dignidade humana não é criação constitucional, porquanto é um elemento preexistente e relacionado com o próprio indivíduo, ou seja, inerente à pessoa, de modo que sua positivação e afirmação foi inserida na atual Constituição brasileira como um dos fundamentos da República Federativa do Brasil para o devido direcionamento do Estado Democrático de Direito. Por isso, chega a ser considerada como direito fundamental e com orientação presente para a fundamentação e interpretação dos demais direitos essenciais previstos na Constituição Federal de 1988.

O conceito kantiano de dignidade é marco para a sua compreensão, por considerar que o ser humano é fim, e não meio (objeto):

O homem, e, duma maneira geral, todo o ser racional, existe como fim em si mesmo, não só como meio para o uso arbitrário desta ou daquela vontade. Pelo contrário, em todas as suas acçôes, tanto nas que se dirigem a ele mesmo como nas que se dirigem a outros seres racionais, ele tem sempre de ser considerado simultaneamente como fim. (KANT, 2007, p. 68).

Pode-se concluir que conceito de dignidade, no tempo contemporâneo, está diretamente ligado ao pensamento filosófico de Immanuel Kant, tanto quanto a sua teoria do imperativo categórico, por consideração à condição do ser humano sempre como um fim para algo e não como um meio, trazendo a ele uma valoração.

A dignidade é um valor natural, correspondente a todos os homens e, por anteceder juízos axiológicos, deve orientar e iluminar o legislador, o intérprete e o aplicador das normas, vinculando de forma absoluta a atividade normativa e a atividade estatal, principalmente no campo penal (PRADO, 2002, p. 116).

Há, a partir da dignidade humana, um "núcleo indestrutível de prerrogativas que o Estado não pode deixar de reconhecer, sendo que esta deve ser a verdadeira esfera de ação dos indivíduos que delimita o poder estatal" (PRADO, 2002, p. 114-115). No mesmo sentido, consoante a exposição de Alexandre de Moraes (2005, p. 16), a dignidade é algo inerente às personalidades humanas e, por tal, deve afastar a ideia de predomínio transpessoalista de Estado e Nação, em detrimento da liberdade individual.

A dignidade "intrínseca" ao homem se manifesta pela capacidade de ele se autodeterminar, livre e plenamente, pressupondo o respeito das demais pessoas diante de um "mínimo invulnerável que todo estatuto jurídico deve assegurar", impondo limites aos seus direitos fundamentais apenas quando inevitável (MORAES, 2005, p. 16).

O conteúdo mínimo da dignidade humana envolve, na compreensão de Barroso (2013, p. 76-98), um valor intrínseco, mais a autonomia e também um valor comunitário. Segundo ele, o valor intrínseco é o elemento ontológico da dignidade humana, 
correspondente ao conjunto das características que são inerentes e comuns a todos os seres humanos, capazes de lhes conferir um status especial e superior no mundo, distinto de outras espécies, valor este que, no plano jurídico, está na origem de um conjunto de direitos fundamentais, o primeiro deles o direito à vida, pré-condição básica para o desfrute de outros direitos, também o direito à integridade física e psíquica, além de outros. A autonomia é o elemento ético, fundamento do livre arbítrio para a busca do viver bem e de ter uma vida boa, numa orientação pessoal e moral relacionada à autodeterminação e, na percepção do autor, também ao mínimo existencial. Por fim, o valor comunitário é o elemento social da dignidade, com contornos moldados pelas relaçóes das pessoas umas com as outras, do papel do Estado e da comunidade no estabelecimento de metas coletivas e restriçóes sobre direitos e liberdades em prol do benefício comum.

A correlação com o direito à vida destaca-se em razão do valor intrínseco da dignidade humana, que "preenche quase inteiramente o conteúdo do direito à vida, deixando espaço apenas para algumas poucas situaçóes específicas e controversas, como o aborto, o suicídio assistido e a pena de morte" (BARROSO, 2013, p. 77).

$\mathrm{Na}$ Ação Direta de Inconstitucionalidade (ADI) no 3.510, o STF (BRASIL, 2010), ao decidir e validar o uso de células tronco embrionárias para pesquisas científicas, entendeu que o embrião só adquire status de ser vivo, após a implantação no útero materno, com a respectiva formação do cérebro:

Ementa: CONSTITUCIONAL. AÇÃO DIRETA DE INCONSTITUCIONALIDADE. LEI DE BIOSSEGURANÇA. IMPUGNAÇÁO EM BLOCO DO ART. 50 DA LEI No 11.105, DE 24 DE MARÇO DE 2005 (LEI DE BIOSSEGURANÇA). PESQUISAS COM CÉLULAS-TRONCO EMBRIONÁRIAS. INEXISTÊNCIA DE VIOLAÇÃO DO DIREITO À VIDA. CONSTITUCIONALIDADE DO USO DE CÉLULAS-TRONCO EMBRIONÁRIAS EM PESQUISAS CIENTÍFICAS PARA FINS TERAPÊUTICOS. DESCARACTERIZAÇÃO DO ABORTO. NORMAS CONSTITUCIONAIS CONFORMADORAS DO DIREITO FUNDAMENTAL A UMA VIDA DIGNA, QUE PASSA PELO DIREITO À SAÚDE E AO PLANEJAMENTO FAMILIAR. DESCABIMENTO DE UTILIZAÇÃO DA TÉCNICA DE INTERPRETAÇÃO CONFORME PARA ADITAR À LEI DE BIOSSEGURANÇA CONTROLES DESNECESSÁRIOS QUE IMPLICAM RESTRIÇÓES ÀS PESQUISAS E TERAPIAS POR ELA VISADAS. IMPROCEDÊNCIA TOTAL DA AÇÃO. [...]. IILEGITIMIDADE DAS PESQUISAS COM CÉLULAS-TRONCO EMBRIONÁRIAS PARA FINS TERAPÊUTICOS E O CONSTITUCIONALISMO FRATERNAL. A pesquisa científica com células-tronco embrionárias, autorizada pela Lei $\mathrm{n}^{\circ} 11.105 / 2005$, objetiva o enfrentamento e cura de patologias e traumatismos que severamente limitam, atormentam, infelicitam, desesperam e não raras vezes degradam a vida de expressivo contingente populacional (ilustrativamente, atrofias espinhais progressivas, distrofias musculares, a esclerose múltipla e a lateral amiotrófica, as neuropatias e as doenças do neurônio motor). [...]. Inexistência de ofensas ao direito à vida e da dignidade da pessoa humana, pois a pesquisa com células-tronco embrionárias (inviáveis biologicamente ou para os fins a que se destinam) significa a celebração solidária da vida e alento aos que se acham à margem do exercício concreto e inalienável dos direitos à felicidade e do viver 
com dignidade (Ministro Celso de Mello). III- A PROTEÇÃO CONSTITUCIONAL DO DIREITO À VIDA E OS DIREITOS INFRACONSTITUCIONAIS DO EMBRIÃO PRÉ-IMPLANTO. O Magno Texto Federal não dispóe sobre o início da vida humana ou o preciso instante em que ela começa. Náo faz de todo e qualquer estádio da vida humana um autonomizado bem jurídico, mas da vida que já é própria de uma concreta pessoa, porque nativiva (teoria "natalista", em contraposição às teorias "concepcionista" ou da "personalidade condicional"). E quando se reporta a "direitos da pessoa humana" e até dos "direitos e garantias individuais" como cláusula pétrea está falando de direitos e garantias do indivíduo-pessoa, que se faz destinatário dos direitos fundamentais “à vida, à liberdade, à igualdade, à segurança e à propriedade”, entre outros direitos e garantias igualmente distinguidos com o timbre da fundamentalidade (como direito à saúde e ao planejamento familiar). Mutismo constitucional hermeneuticamente significante de transpasse de poder normativo para a legislação ordinária. A potencialidade de algo para se tornar pessoa humana já é meritória o bastante para acobertá-la, infraconstitucionalmente, contra tentativas levianas ou frívolas de obstar sua natural continuidade fisiológica. Mas as três realidades não se confundem: o embriāo é o embriāo, o feto é o feto e a pessoa humana é a pessoa humana. Donde não existir pessoa humana embrionária, mas embrião de pessoa humana. $\mathrm{O}$ embrião referido na Lei de Biossegurança ("in vitro" apenas) não é uma vida a caminho de outra vida virginalmente nova, porquanto lhe faltam possibilidades de ganhar as primeiras terminaçôes nervosas, sem as quais o ser humano não tem factibilidade como projeto de vida autônoma e irrepetível. O Direito infraconstitucional protege por modo variado cada etapa do desenvolvimento biológico do ser humano. Os momentos da vida humana anteriores ao nascimento devem ser objeto de proteçâo pelo direito comum. $\mathrm{O}$ embriâo pré-implanto é um bem a ser protegido, mas não uma pessoa no sentido biográfico a que se refere a Constituição. IV- AS PESQUISAS COM CÉLULAS-TRONCO NÃO CARACTERIZAM ABORTO. MATÉRIA ESTRANHA À PRESENTE AÇÃO DIRETA DE INCONSTITUCIONALIDADE. É constitucional a proposição de que toda gestação humana principia com um embrião igualmente humano, claro, mas nem todo embriāo humano desencadeia uma gestaçáo igualmente humana, em se tratando de experimento "in vitro". Situação em que deixam de coincidir concepção e nascituro, pelo menos enquanto o ovócito (óvulo já fecundado) não for introduzido no colo do útero feminino. O modo de irromper em laboratório e permanecer confinado "in vitro" é, para o embrião, insuscetível de progressão reprodutiva. Isto sem prejuízo do reconhecimento de que o zigoto assim extra-corporalmente produzido e também extra-corporalmente cultivado e armazenado é entidade embrionária do ser humano. Não, porém, ser humano em estado de embriấo. A Lei de Biossegurança não veicula autorização para extirpar do corpo feminino esse ou aquele embrião. Eliminar ou desentranhar esse ou aquele zigoto a caminho do endométrio, ou nele já fixado. Não se cuida de interromper gravidez humana, pois dela aqui não se pode cogitar. A "controvérsia constitucional em exame não guarda qualquer vinculaçáo com o problema do aborto." (Ministro Celso de Mello). [...].

A partir deste julgamento, Pedro Lenza (2015, p. 1644) interpretou, sintetizou e assim se posicionou acerca da questão:

o zigoto seria o embriāo em estágio inicial, pois ainda destituído de cérebro. A vida humana começaria com o surgimento do cérebro, que, por sua vez, só apareceria depois de introduzido o embrião no útero da mulher. Assim, antes da introdução no útero não se teria cérebro e, 
portanto, sem cérebro, não haveria vida. Desse modo, estabeleceu o STF que o começo da vida se dá com a existência ou formação do cérebro.

O tratamento jurídico conferido ao direito à vida pode, por decorrência, gerar questionamentos acerca da possibilidade da eutanásia e do abortamento, com polêmicas intensas e até passionais, colocando em lados opostos os defensores da dignidade humana ou o direito de escolha da mulher e os que lutam pelo direito à vida do nascituro ou o paciente em estado terminal. As desavenças não se restringem aos argumentos jurídicos, morais ou de saúde pública, abrangendo também crenças religiosas. No Brasil, náo teria como ser diferente (SARMENTO, 2007, p. 293).

Em síntese, quanto ao abortamento, discussão que se pretende inicialmente, pode-se afirmar que existem os defensores do direito à escolha da mulher e, de outro lado, quem defenda a prevalência do direito à vida.

\section{Conceito de aborto e aborto até o $3^{\circ}$ mês de gestaçáo (STF)}

O Dicionário Aurélio preconiza o conceito de aborto como expulsão de um feto ou embriáo por morte fetal, antes do tempo e sem condiçóes de vitalidade fora do útero materno (FERREIRA, 2010). Portanto, o abortamento é a interrupçáo da gravidez com a destruição do produto da concepçáo.

O Código Penal não define claramente o crime de aborto e utiliza apenas a expressão provocar aborto, razão pela qual cumpre à doutrina o papel de conferir um melhor esclarecimento acerca da amplitude da tipicidade do ato ilícito e culpável.

Para Aníbal Bruno (1976, p. 160), provocar aborto é interromper o processo fisiológico da gestação, com a consequente morte do feto. Mais preciso, Frederico Marques (1997, p. 183) leciona que, para o Direito Penal e do ponto de vista médico-legal, o aborto é a interrupção voluntária da gravidez, com a morte do produto da concepçáo.

Ensina-nos Capez (2014, p. 161):

Considera-se aborto a interrupção da gravidez com a consequente destruição do produto da concepção. Consiste na eliminação da vida intrauterina. Não faz parte do conceito de aborto, a posterior expulsão do feto, pois pode ocorrer que o embriāo seja dissolvido e depois reabsorvido pelo organismo materno, em virtude de um processo de autólise; ou entáo pode suceder que ele sofra processo de mumificação ou maceraçáo, de modo que continue no útero materno. A lei não faz distinção entre o óvulo fecundado (3 primeiras semanas de gestação), embrião (3 primeiros meses), ou feto (a partir de 3 meses), pois em qualquer fase da gravidez estará configurado o delito de aborto, quer dizer desde o início da concepção até o início do parto.

A doutrina brasileira define as espécies de aborto e, dentre elas, pode-se observar a existência ou não de aborto decorrente de práticas proibidas, em situaçóes que sáo previstas no Código Penal. 
- Aborto Natural: Interrupção da gravidez independentemente da vontade humana, isto é, ocorre o aborto como consequência de uma causa natural ou em razão de alguma enfermidade, razão pela qual não é crime.

-Aborto Acidental: Este aborto acidental é decorrente de quedas ou traumatismos em geral. Também é fato atípico, não é considerado como crime.

- Aborto Criminoso: é praticado intencionalmente, ou seja, decorre do dolo daquele que tem a intençâo de interromper a gravidez por qualquer motivo (CAPEZ, 2014).

O Código Penal brasileiro estabelece as seguintes modalidades criminosas de aborto:
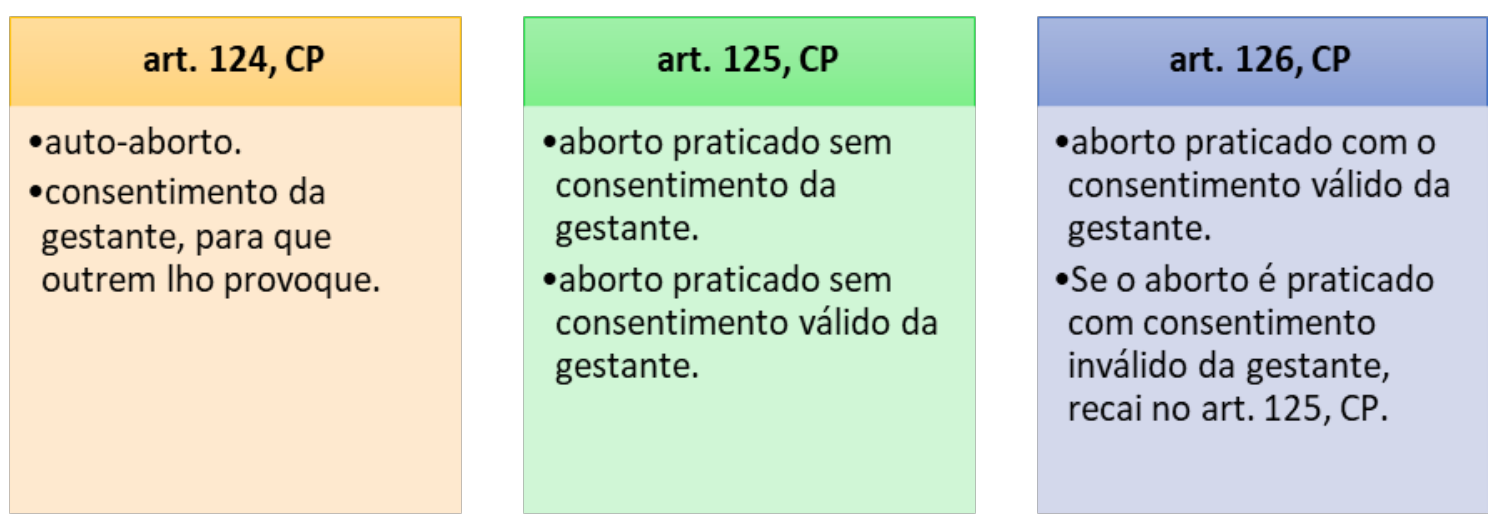

Portanto, o significado de abortamento é de "privação do nascimento", já que a gestante priva voluntariamente o feto de nascer com vida, sob a ótica geral, descartandose o aborto sob a análise de saúde pública ou anomalia. Costumou-se a empregar a palavra aborto ao crime, muito embora aborto seja o produto da açáo de abortamento. A doutrina e a legislação empregam a palavra aborto igualmente para a açáo de abortamento, de maneira que ambos os vocábulos podem ser utilizados como sinônimos.

Conquanto haja normas que proíbem provocar aborto, o STF, no Habeas Corpus no 124.306/RJ, entendeu que o abortamento até o terceiro mês da gestaçáo não é crime. Trata-se de julgado da $1^{a}$ Turma do STF, não do Plenário, de maneira que esta compreensão ainda não se apresenta para aplicaçáo geral, mas específica a um caso concreto no âmbito de uma das Turmas. Náo se aplica a todo e qualquer caso análogo, muito embora, por óbvio, como toda decisão do STF, pode ser suscitada como um entendimento que pode vir a se tornar um importante precedente.

No caso em concreto, o Habeas Corpus no 124.306/RJ foi impetrado para revogação da prisão preventiva de cinco pessoas, processadas pelo crime de aborto, praticado em uma clínica clandestina em Duque de Caxias/RJ. A defesa alegou a descriminalização do ato e, em 2014, o Ministro Marco Aurélio concedeu limitar para que cinco médicos e cinco funcionários da clínica fossem soltos, porquanto estavam presos preventivamente.

No julgamento da demanda, o STF decidiu, especificamente para o caso, não estar configurada a caracterização de crime, pois os abortos foram realizados nas fases 
iniciais do desenvolvimento gestacional. Nota-se que o critério adotado para a considerar fato típico não foi a nidação, tal qual ocorrera no julgamento que admitiu pesquisas com células-tronco embrionárias, mas um momento posterior. Como crítica, não podemos concordar com a possibilidade da prática de aborto além do segundo mês de gestação, pois, com a diferenciação celular, o cérebro do feto já terá formação entre a $8^{\mathrm{a}}$ e a $12^{\mathrm{a}}$ semana de gestação (COSTA, 2016, p. 33-37), de tal forma que as terminaçóes nervosas dos neurônios receberão as transmissóes químicas que levam às sensaçóes da dor, do sofrimento e da consciência. Se o fim da vida ocorre com a morte cerebral, a adoçáo de critério semelhante para assegurar tutela em momento posterior à nidação só poderia ocorrer com a formação do sistema nervoso central.

Apresenta-se a ementa do julgado (BRASIL, 2016) para melhor compreensão:

Ementa: DIREITO PROCESSUAL PENAL. HABEAS CORPUS. PRISÃO PREVENTIVA. AUSÊNCIA DOS REQUISITOS PARA SUA DECRETAÇÃO. INCONSTITUCIONALIDADE DA INCIDÊNCIA DO TIPO PENAL DO ABORTO NO CASO DE INTERRUPÇÃO VOLUNTÁRIA DA GESTAÇÃO NO PRIMEIRO TRIMESTRE. ORDEM CONCEDIDA DE OFÍCIO. 1. O habeas corpus não é cabível na hipótese. Todavia, é o caso de concessão da ordem de ofício, para o fim de desconstituir a prisão preventiva, com base em duas ordens de fundamentos. 2 . Em primeiro lugar, não estão presentes os requisitos que legitimam a prisão cautelar, [...]. Os acusados são primários e com bons antecedentes, têm trabalho e residência fixa, têm comparecido aos atos de instrução e cumprirão pena em regime aberto, na hipótese de condenação. 3. Em segundo lugar, é preciso conferir interpretação conforme a Constituição aos próprios arts. 124 a 126 do Código Penal - que tipificam o crime de aborto - para excluir do seu âmbito de incidência a interrupção voluntária da gestação efetivada no primeiro trimestre. A criminalização, nessa hipótese, viola diversos direitos fundamentais da mulher, bem como o princípio da proporcionalidade. 4. A criminalização é incompatível com os seguintes direitos fundamentais: os direitos sexuais e reprodutivos da mulher, que não pode ser obrigada pelo Estado a manter uma gestaçấo indesejada; a autonomia da mulher, que deve conservar o direito de fazer suas escolhas existenciais; a integridade fisica e psíquica da gestante, que é quem sofre, no seu corpo e no seu psiquismo, os efeitos da gravidez; e a igualdade da mulher, já que homens não engravidam e, portanto, a equiparação plena de gênero depende de se respeitar a vontade da mulher nessa matéria. 5. A tudo isto se acrescenta o impacto da criminalizaçáo sobre as mulheres pobres. É que o tratamento como crime, dado pela lei penal brasileira, impede que estas mulheres, que não têm acesso a médicos e clínicas privadas, recorram ao sistema público de saúde para se submeterem aos procedimentos cabíveis. Como consequência, multiplicam-se os casos de automutilação, lesóes graves e óbitos. 6. A tipificação penal viola, também, o princípio da proporcionalidade por motivos que se cumulam: (i) ela constitui medida de duvidosa adequação para proteger o bem jurídico que pretende tutelar (vida do nascituro), por não produzir impacto relevante sobre o número de abortos praticados no país, apenas impedindo que sejam feitos de modo seguro; (ii) é possível que o Estado evite a ocorrência de abortos por meios mais eficazes e menos lesivos do que a criminalização, tais como educação sexual, distribuição de contraceptivos e amparo à mulher que deseja ter o filho, mas se encontra em condiçóes adversas; (iii) a medida é desproporcional em sentido estrito, por gerar custos sociais (problemas de saúde pública e mortes) superiores aos seus benefícios. 7. 
Anote-se, por derradeiro, que praticamente nenhum país democrático e desenvolvido do mundo trata a interrupção da gestação durante o primeiro trimestre como crime, aí incluídos Estados Unidos, Alemanha, Reino Unido, Canadá, França, Itália, Espanha, Portugal, Holanda e Austrália. 8. Deferimento da ordem de ofício, para afastar a prisão preventiva dos pacientes, estendendo-se a decisão aos corréus.

Em seu voto, o Relator Ministro Barroso fez as seguintes ponderaçóes:

a) A autonomia da mulher, sua integridade física e psíquica, seus direitos sexuais e reprodutivos e a igualdade de gênero, imputa que a ela não seja obrigada a carregar o ônus integral de uma gravidez;

b) Homem não engravida. Assim, somente haverá igualdade plena, quando for conferido à mulher o direito de decidir acerca da manutenção ou náo do estado gestacional;

c) A criminalização do aborto causa uma discriminação contra as mulheres pobres, as quais não podem recorrer a um procedimento médico e seguro. Enquanto as que possuem condiçôes pagam clínicas particulares.

d) O sistema nervoso central do feto, nos estágios iniciais da gestação, ainda não está formado. Portanto, não existe nenhum dano a prática do procedimento abortivo.

e) A decisão não defende o aborto nem propõe a disseminação do aborto. É uma decisão para que se adotem políticas públicas melhores do que a criminalização para evitar o aborto.

Portanto, assim, como os abortos foram realizados no início da fase gestacional, até o terceiro mês, não há crime algum.

Os direitos da personalidade apresentam uma evolução em face do maior reconhecimento deles na atualidade, o que também ocorre com relação ao direito à vida, de maneira que as pessoas começaram a visualizar inclusive a possibilidade do direito de morrer e, ainda, decidir se vão viver, principalmente em razão do sofrimento havido por enfermos em estado terminal. Por conseguinte, em uma sociedade que valoriza a autonomia da vontade, ante a imensurável evolução tecnológica, há o desencadear constante de crises no que tange às tradicionais reflexóes sobre a vida e a morte (OTERO, 2004, p. 17).

Acentua-se a colisão entre o direito à vida e outros direitos constitucionalmente reconhecidos, como a dignidade humana, a liberdade religiosa, a liberdade e autonomia da mulher, além de outros bens juridicamente protegidos, de tal maneira que se torna viável realizar um balanceamento para verificar qual será avaliado com maior peso na incidência jurídica em casos concretos. 


\section{0 abortamento clandestino como problema de saúde, o direito à vida da gestante e a necessidade de políticas públicas de proteção à mulher}

Toda pessoa tem direito a uma vida digna, que deve ser garantida pelo Estado diante daquilo que se encontra previsto na Constituição Federal de 1988. Nesse sentido, de forma complementar ao direito à vida e à integridade física e mental, o direito à saúde é estabelecido como um direito fundamental social, também assegurado constitucionalmente, inclusive pormenorizadamente dentre os assuntos relacionados à Ordem Social.

Com efeito. A Constituição Federal de 1988 arrola o direito à saúde dentre os direitos fundamentais sociais, ao lado da educação, da alimentação, do trabalho, da moradia, do transporte, do lazer, da segurança, da previdência social, da proteção à maternidade e à infância, da assistência aos desamparados, ao passo que, no art. 196, mais detalhadamente, a saúde é estabelecida como um direito pertinente a todos, sendo dever do Estado garanti-la, por intermédio de políticas sociais e econômicas que busquem a "[...] redução do risco de doença e de outros agravos e ao acesso universal e igualitário às ações e serviços para sua promoção, proteção e recuperação” (BRASIL, 1988).

O direito à saúde tem grande importância no ordenamento jurídico pátrio, como obrigaçáo do Estado de promovê-lo, com fundamento nos direitos sociais, buscando sempre o bem-estar e a qualidade de vida de seus cidadãos, porquanto a saúde é considerada como o "bem-estar físico, espiritual e mental das pessoas, e, quando o Poder Público protege a saúde, está, por via de consequência direta, protegendo a vida” (ZAGANELLI et al., 2016, p. 5).

A fim de atender à política pública de saúde para todos, prevista constitucionalmente de modo que o Estado passasse a prestar o direito coletivo à saúde aos cidadãos, foi instituído o Sistema Único de Saúde (SUS), em conformidade com o art. 200 da Constituição Federal.

O SUS foi estruturado e regulamentado pelo legislador infraconstitucional por intermédio da Lei no 8.080/1990, que "dispóe sobre as condiçóes para a promoção, proteção e recuperação da saúde, a organização e o funcionamento dos serviços correspondentes" (BRASIL, 1990). De acordo com o art. 30 da referida legislação, a saúde compreende, como "determinantes e condicionantes, entre outros, a alimentação, a moradia, o saneamento básico, o meio ambiente, o trabalho, a renda, a educação, a atividade física, o transporte, o lazer e o acesso aos bens e serviços essenciais" (BRASIL, 1990).

$\mathrm{Na}$ realidade pátria contemporânea, milhares de pessoas não possuem sequer condições mínimas para viver uma vida digna e de qualidade. Nesse sentido, o sistema público de saúde tem-se mostrado seletivo em face da falta ou precariedade de 
infraestrutura, e da escassez de recursos à saúde, como a experiência contemporânea tem evidenciado não apenas no Brasil, mas até em países do primeiro mundo. Não se pode, todavia, desprezar a enorme quantidade de pessoas atendidas e tratadas diariamente no SUS brasileiro, por vezes com boa qualidade nos serviços prestados, apesar de não se verificar o mesmo em muitas outras unidades de atendimento.

A deficiência do Sistema de Seguridade pode ser constatada, muitas vezes, não tanto pela prestação de serviços em si, mas em função da ausência de políticas públicas que impeçam, preventivamente, o aparecimento de contingências sociais, como no acompanhamento das mulheres e gestantes. Esta deficiência, ao lado da tipificação penal da prática do aborto, leva muitas mulheres a buscar a realizaçáo de abortamentos clandestinos e inseguros, em especial as pessoas carentes, conforme se observa, inclusive, em um dos fundamentos apresentados pelo Ministro Barroso no Habeas Corpus no 124.306/RJ.

Um dia após a $1^{\text {a }}$ Turma do STF entender que não é crime a interrupção da gravidez até o $3^{\circ}$ mês de gestação, o Ministro Relator do julgado assim se manifestou em entrevista:

É uma decisão para que se adotem políticas públicas melhores do que a criminalização para evitar o aborto. É uma decisão importante para deflagrar um debate que já não deveria mais ser adiado. Em uma democracia, nenhum tema é tabu. A decisão não defende o aborto nem propóe a disseminação do aborto. É uma decisão para que se adotem políticas públicas melhores do que a criminalização para evitar o aborto (BARROSO, 2016).

Em conferências internacionais, de População e Desenvolvimento no Cairo (em 1994), e sobre a Mulher em Pequim (1995), a provocação do aborto em condiçóes inseguras foi incluída como questão de saúde pública e os países signatários, como o Brasil, assumiram compromisso de implementar serviços para a redução da mortalidade (FRIEDE, 2018). Após uma década, todavia, segundo dados da Pesquisa Nacional de Aborto de 2016, ao menos uma a cada cinco brasileiras de todas as classes sociais com até 40 anos realizaram abortamentos, a maioria praticados no centro do período reprodutivo entre 18 e 29 anos de idade, mães separadas de baixa escolaridade e renda, trabalhadoras, negras/pardas ou indígenas (DINIZ et al, 2017). Mesmo com redução da taxa de abortamentos inseguros, a permanência do crime do aborto ainda leva mulheres a realizarem clandestinamente a prática, muitas em clínicas sem higiene, com grave risco de óbito das gestantes.

São fundamentos para a adoção de uma política de saúde reprodutiva, até mesmo preventiva, e com o objetivo de eliminar abortos provocados de maneira insegura:

Alguns tratados internacionais de direitos humanos que preveem $o$ direito de todas as pessoas de ter acesso ao maior padrão de saúde possivel; 
O direito da mulher e a liberdade de decidir responsavelmente o número de filhos, espaçamento e o momento de terem filhos, e $o$ direito de receberem informaçóes e ainda $o$ direito de abortamento seguro;

$\mathrm{O}$ direito das mulheres de controlar e decidir livre em relação à sua sexualidade, incluindo a saúde sexual e reprodutiva, sem coerção e discriminação;

O direito de ter acesso à todas as informações relevantes sobre saúde;

O direito de cada pessoa de usufruir dos benefícios dos avanços científicos e suas aplicaçóes.

O uso de qualquer método anticoncepcional entre as mulheres. (MERELES, 2016)

O julgamento do STF coincidentemente ocorreu após a Anistia Internacional divulgar e defender, em 2014, que o aborto deveria ser tratado como um problema de saúde pública e de direitos humanos, e não criminal, principalmente com a constatação de que um milhão de brasileiras procederam a abortamentos em clínicas clandestinas, muitas das quais faleceram em razão da cirurgia ou das respectivas manobras, quinta maior causa de morte entre as mulheres (ANISTIA INTERNACIONAL, 2014).

Há algumas políticas públicas adotadas no Brasil com relação ao planejamento familiar e aos cuidados com a mulher, porém ainda se mostram insuficientes para conscientizar e evitar uma gravidez indesejada.

A Rede Cegonha, por exemplo, foi instituída no âmbito do Sistema Único de Saúde pela Portaria no 1.459/2011 do Ministério da Saúde (BRASIL, 2011a), consistente numa rede de cuidados que visa a assegurar à mulher o direito ao planejamento reprodutivo $\mathrm{e}$ à atenção humanizada à gravidez, ao parto e ao puerpério, bem como à criança o direito ao nascimento seguro e ao crescimento e ao desenvolvimento saudáveis. Tem a finalidade de fomentar a implementação de um novo modelo de atenção à saúde da mulher e à saúde da criança com foco na atenção ao parto, ao nascimento, ao crescimento e ao desenvolvimento da criança de zero aos 24 meses, mas também de organizar uma Rede de Atenção à Saúde Materna e Infantil que garanta acesso, acolhimento e resolutividade, além de reduzir a mortalidade materna e infantil. Como princípio, tem-se o acolhimento e classificação de risco, ampliação do acesso e melhoria da qualidade do pré-natal, vinculação da gestante à unidade de referência e ao transporte seguro, boas práticas e segurança na atençáo ao parte e nascimento (campo dos direitos humanos), atençáo à saúde das crianças até 24 meses de idade com qualidade e resolutividade, assim como o acesso ao planejamento reprodutivo dentro de uma política mais ampla de atenção integral à saúde da mulher e à saúde da criança.

Já o Sistema Nacional de Cadastro, Vigilância e Acompanhamento de Gestantes e Puérperas para Prevenção da Mortalidade Materna, conforme foi estabelecido pela Medida Provisória no 557/2011, autorizava a União a conceder benefício financeiro, bem como 
tinha como finalidade a prevenção da mortalidade materna, a ser coordenada e executada pelo Sistema Único de Saúde, para garantir a melhoria do acesso, da cobertura e da qualidade da atenção à saúde materna, notadamente nas gestações de risco (BRASIL, 2011b). A gestão desse Sistema seria realizada por meio das seguintes instâncias: Comitê Gestor Nacional e comissóes de cadastro, vigilância e acompanhamento de gestantes e puérperas de risco, competindo a estas, entre outras atribuiçóes, cadastrar em sistema informatizado os dados de todas as gestantes e puérperas atendidas nos serviços de estabelecimento de saúde. Esse cadastramento tem como finalidade acompanhar todo o estágio da gravidez da gestante, proporcionando-lhe atendimento médico em todas as necessidades. Foi autorizada, ainda, a instituição de um benefício financeiro no valor de R \$ 50,00 para gestantes cadastradas no Sistema, com o objetivo de auxiliar o seu deslocamento e seu acesso às açóes e aos serviços de saúde relativos ao acompanhamento do pré-natal e assistência ao parto prestados pelo SUS. Em junho de 2012, a Medida Provisória teve a vigência encerrada.

A adoção de políticas públicas não terá como efeito imediato a conscientização das pessoas de maneira a evitar gravidez indesejada, até mesmo porque nem a tipificação da conduta como crime impede a sua prática, assim como a possibilidade de contrair doenças venéreas como a AIDS. O desenvolvimento de novas políticas públicas na área da saúde demandaria um constante contato com as mulheres, com resultados efetivos após um longo período de efetivação.

Sem políticas públicas que revelem resultados efetivos e imediatos ante a ocorrência sucessiva de morte de mulheres que se submetem a abortamentos clandestinos, propóese agora como possível solução a descriminalização da conduta, pois o direito à vida da mulher também deve ser assegurado. Com a realização de cirurgias em ambientes hospitalares, o risco de morte de gestantes diminuiria, além do que o Estado poderia prestar assistência à mulher de forma prévia ou mesmo na sequência, inclusive com acompanhamento multidisciplinar e para apresentar alternativas de forma a assegurar uma possível manutenção da gestação.

\section{0 consideraçóes finais}

$\mathrm{Na}$ Antiguidade, como o feto não recebia proteção jurídica por ser considerado extensão ou anexo ao corpo da mulher, o abortamento foi permitido até o advento do cristianismo, quando o ato de abortar passou a ser reprovado no meio social e proibido juridicamente na segunda metade do Império Romano. O forte poder da Igreja manteve a reprovação ao abortamento a partir da Idade Média.

No Brasil, o abortamento realizado pela gestante não era considerado como crime, pois o Estado entendia que a mulher era proprietária de seu próprio corpo e poderia 
livremente dele dispor, com a faculdade de continuar ou não a gravidez, sem ser imposto nenhum tipo de sanção.

O abortamento foi objeto de inculpação no Brasil após o advento do Código Penal do Império de 1830, que classificou o ato de provocar aborto como crime grave, porquanto ofendia a segurança das pessoas. Os arts. 199 a 200 detalhavam dois tipos de figuras criminosas, a saber, o aborto consentido e o aborto sofrido, embora o aborto provocado não fosse punido.

O referido Código punia apenas quem praticava aborto, mas não quem o consentia, de maneira que a pena variava de 1 a 5 anos, sendo dobrada se o crime fosse praticado sem o consentimento da gestante.

No ano de 1890, passou a vigorar o Código Penal da República e, com ele, houve a tipificação criminal do autoaborto, ao restar diferenciado o aborto com exclusão do feto da figura do agravamento em decorrência da morte da gestante.

Com o Código Penal de 1940, restaram tipificadas várias figuras ou maneiras de abortar, consoante as ações comissivas presentes nos arts. 124, 125, 126, 127 e 128. É oportuna a ressaltava de que o Código foi publicado segundo a cultura, costumes e hábitos da década de 30 .

A Igreja Católica e uma boa parte das Igrejas Evangélicas sempre se colocam contra o aborto em qualquer dos casos. Ambas pregam que a vida deve ser protegida. Doutrinam que Deus é o autor e consumador das vidas, e apenas a Ele é conferido o direito de as interromper. As religióes ora em comento são contra até mesmo à interrupção da gravidez na hipótese de se constatar a existência de feto anencefálico.

A discussão acerca da possibilidade ou não da interrupção da gestação de feto até o terceiro mês de gestação chegou até o STF por meio do Habeas Corpus n. ${ }^{\circ}$ 124306/RJ, no qual se debateu acerca da adoção de políticas públicas, ao invés de estabelecer crimes para evitar abortos. $\mathrm{Na}$ fundamentação, a Corte direcionou-se ao fim dos abortamentos clandestinos, que mutilam e levam à morte muitas mulheres, pois a tipificação do crime de provocar o abortamento é um mecanismo de discriminação social, que produz desigualdade sobre as mulheres pobres, sem acesso à medicação adequada e à informação.

A decisão náo descriminaliza o abortamento e nem cria uma exceçáo ao ato criminoso contido no Código Penal, pois o julgamento não tem efeito erga omnes e também não foi realizado pelo Plenário do STF, mas não há dúvida de que foi tomada uma deliberação relevante que poderá vir a formar um novo precedente na disciplina da matéria.

É importante salientar que ausência de informaçóes, métodos preventivos e cuidados básicos exclusivamente à mulher pode prejudicar a saúde física da gestante e ocasionar sérios problemas psicológicos, pois é pertinente considerar que a perda de um 
filho, mesmo em decorrência de um abortamento deliberado, normalmente acarreta sofrimento.

Não está em foco apenas o direito à vida do feto, pois o estabelecimento do crime de aborto trouxe, como consequência, a busca pelas mulheres mais pobres por clínicas clandestinas para realização do ato, com grande risco para as suas vidas em razão da falta de condições de higiene e de aparelhagem suficiente para a solução de intercorrências.

Sob o aspecto de assegurar a vida das mulheres, por ser o Estado laico, o STF decidiu adequadamente ao permitir a interrupção da gestação, com o emprego da técnica da proporcionalidade ao considerar a prevalência da autonomia reprodutiva da mulher e do seu direito à saúde, como ato decorrente de exercício regular de um direito, bem como sob o fundamento de que o aborto é um problema da saúde em face da ausência de políticas públicas apropriadas à mulher no Brasil. Compreendemos ser tardio apenas o critério eleito pela Corte de permitir o abortamento além do segundo mês de gestação, pois o cérebro estará formado e sensações serão sentidas pelo feto, com sofrimento.

\section{Referências}

ANISTIA INTERNACIONAL. Aborto é questão de saúde pública, e não criminal, defende Anistia Internacional. 24 set. 2014. Disponível em: https://anistia.org. $\mathrm{br} /$ noticias/aborto-e-questao-de-saude-publica-e-nao-criminal-defende-anistiainternacional/. Acesso em: $10 \mathrm{dez} .2018$.

BARROSO, Luís Roberto. A dignidade da pessoa humana no Direito Constitucional contemporâneo: construção de um conceito jurídico à luz da jurisprudência mundial. Tradução: Humberto Laport de Mello. Belo Horizonte: Forum, 2013.

BARROSO, Luís Roberto. 'Decisão (sobre aborto) é para adotar políticas públicas', diz Barroso. [Entrevista concedida a] O Estado de São Paulo, 01 dez. 2016. UOL notícias. Ciência e Saúde. Disponível em: https://noticias.uol.com.br/saude/ultimas-noticias/ estado/2016/12/01/decisao-sobre-aborto-e-para-adotar-politicas-publicas-diz-barroso. htm?cmpid=copiaecola\&cmpid=copiaecola. Acesso em: $12 \mathrm{dez} .2017$.

BITENCOURT, Cezar Roberto. Tratado de Direito Penal. 6. ed. São Paulo: Revista dos Tribunais, 2007.

BRASIL. Código Penal do Império do Brazil. Lei de 16 de dezembro de 1830. Manda executar o Código Criminal. Colecção de Leis do Império do Brazil. Rio de Janeiro: Typographia Nacional, 1878, v. 1, p. 42. Disponível em: http:/www.planalto.gov.br/ ccivil_03/leis/lim/LIM-16-12-1830.htm. Acesso em: 05 dez. 2017. 
BRASIL. Constituição (1988). Constituição da República Federativa do Brasil de 1988. Diário Oficial da Uniáo. Disponível em: http://www.planalto.gov.br/ccivil_03/ constituicao/constituicao.htm. Acesso em: 05 dez. 2017.

BRASIL. Decreto no 678, de 6 de novembro de 1992. Promulga a Convenção Americana sobre Direitos Humanos (Pacto de San José da Costa Rica), de 22 de novembro de 1969. Diário Oficial da União, Brasília, DF, 9 nov. 1992. Disponível em: http://www.planalto.gov.br/ccivil_03/decreto/d0678.htm. Acesso em 21 mar. 2018.

BRASIL. Lei no 10.406, de 10 de janeiro de 2002. Institui o Código Civil. Diário Oficial da União. Brasília, DF, 11 jan. 2002. Disponível em: http://www.planalto.gov. br/ccivil_03/leis/2002/110406.htm. Acesso em 08 nov. 2018.

BRASIL. Supremo Tribunal Federal (Plenário). Ação Direita de Inconstitucionalidade ADI no 3510/DF. Relator: Ministro Ayres Brito, 29 maio 2008. DJe no 96, 27 maio 2010. Disponível em: http://redir.stf.jus.br/paginadorpub/paginador. jsp?docTP=AC\&docID=611723. Acesso em: 30 nov. 2018.

BRASIL. Portaria no 1459 de 24 de junho de 2011. Institui, no âmbito do Sistema Único de Saúde - SUS - a Rede Cegonha. Diário Oficial da União. 2011a. Disponível em: http://bvsms.saude.gov.br/bvs/saudelegis/gm/2011/prt1459_24_06_2011.html. Acesso em: 13 dez. 2017.

BRASIL. Câmara dos Deputados. Medida Provisória no 557, de 26 de dezembro de 2011. 2011b. Disponível em: http://www.camara.gov.br/proposicoesWeb/ fichadetramitacao?idProposicao=533510. Acesso em: $13 \mathrm{dez} .2017$.

BRASIL. Supremo Tribunal Federal (1 a Turma). Habeas Corpus no 124.306/RJ. Impetrante: Jair Leite Pereira. Pacientes : $\quad$ Edilson dos Santos; Rosemere Aparecida Ferreira. Coator: Superior Tribunal de Justiça. Relator: Ministro Marco Aurélio, 29 nov. 2016. Disponível em: http://redir.stf.jus.br/paginadorpub/paginador. jsp?docTP=TP\&docID=12580345. Acesso em: 09 dez. 2018

BRUNO, Aníbal. Crimes contra a pessoa. 4. ed. Rio de Janeiro: Editora Rio, 1976.

CAPEZ, Fernando. Curso de Direito Penal. 14. ed. São Paulo: Saraiva, 2014.

CIC. Catecismo da Igreja Católica. 3. ed. Petrópolis, RJ: Vozes; São Paulo: Paulinas, Loyola, Ave-Maria, 1993.

COSTA, Liliana Patrícia Teixeira da. Alteraçóes encefálicas no $2^{\circ}$ trimestre de fetos com trissomia 21: avaliação de casos de interrupção médica de gravidez. 2016. Dissertação/ Tese (Mestrado em Medicina e Oncologia Molecular). Faculdade de Medicina, Universidade do Porto. Porto, 2016. Disponível em: https://repositorio-aberto.up.pt/ bitstream/10216/103755/2/189021.pdf. Acesso em: 11 dez. 2018. 
DINIZ, Maria Helena. Curso de Direito Civil brasileiro. 22. ed. São Paulo: Saraiva, 2007.

DINIZ, Maria Helena. O estado atual do biodireito. 8. ed. São Paulo: Saraiva, 2011.

DINIZ, Débora; MEDEIROS, Marcelo; MADEIRO, Alberto. Pesquisa Nacional de Aborto 2016. Ciência \& Saúde Coletiva, Rio de Janeiro, v. 22, n. 2, p. 653-660, fev. 2017. Disponível em: http://www.scielo.br/pdf/csc/v22n2/1413-8123-csc-22-02-0653. pdf. Acesso em: 27 jul. 2019.

DWORKIN, Ronald. Dominio da vida: aborto, eutanásia e liberdades individuais. Tradução de Jefferson Luiz Camargo. 2. ed. São Paulo: Martins Fontes, 2009.

FACHIN, Luiz Edson. Estatuto jurídico do patrimônio mínimo. Rio de Janeiro: Renovar, 2001.

FERREIRA, Aurélio Buarque de Holanda. Dicionário da lingua portuguesa. 5. ed. Curitiba: Positivo, 2010.

FRIEDE, Reis. Aborto: uma questão jurídica e de saúde pública. Revista Jus Navigandi, Teresina, ano 23, n. 5398, 12 abr. 2018. Disponível em: https://jus.com.br/ artigos/65271. Acesso em: 27 jul. 2019.

KANT, Immanuel. Fundamentação da metafísica dos costumes. Tradução: Paulo Quintela. Edições 70, 2007.

LENZA, Pedro. Direito Constitucional esquematizado. 19. ed. São Paulo: Saraiva, 2015. MARQUES, José Frederico. Tratado de Direito Penal. Campinas: Bookseller, 1977, v. II.

MERELES, Carla. Aborto: entenda tudo sobre essa questão. Politize! 17 nov. 2016. Disponível: https://www.politize.com.br/aborto-entenda-essa-questao/. Acesso em: 29 jul. 2019.

MORAES, Alexandre de. Direito Constitucional. 17. ed. São Paulo: Atlas, 2005.

ORGANIZAÇÃO DOS ESTADOS AMERICANOS (OEA). Convenção Americana sobre Direitos Humanos. Disponível em: http://www.planalto.gov.br/ccivil_03/ decreto/1990-1994/anexo/and678-92.pdf. Acesso em: 21 mar. 2018.

OTERO, Paulo. Direito da vida. Coimbra: Almedina, 2004.

PARANÁ. Tribunal de Justiça do Estado do Paraná (1 ${ }^{a}$ Câmara Criminal). Apelação Crime no 628.358-1 da 1a Vara Criminal de Cascavel. Apelante: Ministério Público. Interessados: Werediana Raizer Naschke; Ari Malafiga. Relator: Desembargador Campos Marques, 04 de março de 2010. Pesquisa de jurisprudências. Disponível em: https://www.tjpr.jus.br/consulta-2grau. Acesso em: 09 dez. 2018. 
PONTES DE MIRANDA, Francisco Cavalcante. Tratado de Direito Privado. Atualizada por Vilson Rodrigues Alves. Campinas: Bookseller, 2000, Tomo VII.

PRADO, Luiz Régis. Curso de Direito Penal brasileiro. 3. ed. São Paulo: Revista dos Tribunais, 2002.

ROSSATO, Luciano Alves. Presidente Dilma institui, por medida provisória, sistema nacional de cadastro, vigilância e acompanhamento de gestante e puérpera para prevenção da mortalidade materna. 2011. JUSBRASIL. Disponível em: https:// lucianorossato.jusbrasil.com.br/artigos/121817388/presidente-dilma-institui-pormedida-provisoria-sistema-nacional-de-cadastro-vigilancia-e-acompanhamento-degestante-e-puerpera-para-prevencao-da-mortalidade-materna. Acesso em: 13 dez. 2017.

SARLET, Wolfgang Ingo. Dignidade da pessoa humana e direitos fundamentais na Constituição da República de 1988. Porto Alegre: Livraria do Advogado, 2002.

SARMENTO, Daniel. GALDINO, Flávio. Direitos Fundamentais: estudos em homenagem ao professor Ricardo Lobo Torres. Rio de Janeiro: Renovar, 2006.

SZANIAWSKI, Elimar. Direitos de personalidade e sua tutela. 2. ed. São Paulo: Revista dos Tribunais, 2005.

VENOSA, Sílvio de Salvo. Direito Civil: Parte Geral. 14. ed. São Paulo: Atlas, 2014.

ZAGANELLI, Margareth Vetis et al. "Morte miserável" e a judicialização da saúde. Derecho y Cambio Social, Lima, Peru, n. 43, ano XIII, 2016. Disponível em: https:// www.derechoycambiosocial.com/revista043/EUTANASIA_SOCIAL.pdf. Acesso em: 26 jul. 2019. 